\title{
11 Dealing with Institutions and Policy Makers
}

Tomasz Wicherkiewicz

Revitalization of a language is a combination of ideas and actions that focus on the language system itself, language users, their attitudes to the language, as well as the methods and domains of language acquisition and usage. Language communities, though, never function in isolation and rarely can fully decide on the future of their language. Most revitalization efforts are eventually confronted with authorities and official policy makers. These higher institutions usually represent the state, whose dominant language is different from the language being revitalized. Obviously the language policies of these institutions do not deal solely with endangered languages. What is more, they usually focus on maintaining and supporting the national, official, dominant languages of the state. The communities who endeavor to revive and strengthen their languages often launch their own strategies, that is they also have a language policy.

Language policies are decisions, positions, and principles regarding language, its nature, and role - any actions that affect language use and usage. This might include language education, writing and spelling, or the choice of language(s) in the public space.

When we think about language policies, we usually mean state or administrative language policies, or 'TOP-DOWN' policies as they are known. On the other hand, all parts of society have language policies, for example, schools, commercial companies, communities, language movements, families, and even individuals. These are called 'воттом-uP' language policies. Both kinds of policy may be either overt or implicit and unstated, and they are often based on language ideologies (see Chapter 7). Nevertheless, the most powerful and influential parties are often INSTITUTIONS and/or other 'top-down' POLICY MAKERS.

The political concepts and practices of nation states were born and developed in Europe, and are commonly reproduced in other parts of the world. The simplistic image of a 'nation state' functioning in just one 'statenational' language has been destructive for language diversity; TOP-DOWN language policy has been widely used as a crucial part of nation building, 
and these 'TOP-DOWN' policies have largely been based on the imposition of one 'superior' language over lesser 'vernaculars' or 'dialects'.

Traditionally 'nation states' have been key players in the design and implementation of language policy. In fact, the role of the state has both increased and become more nuanced, as new 'agenda-setting' political actors have emerged, both in supranational institutions and agencies, and in subnational (regional, interregional, municipal) administrative bodies and organizations.

The relationship between states, societies, and the economic sector has altered profoundly; social-economic factors now play a much more prominent role in institutional negotiations and affect power relations in language revitalization, maintenance, and planning. For example, recently, there has been growing interest among large (global) retail chains, some financial companies, and local small businesses, in using nonofficial, coofficial, and semiofficial languages (languages recognized and used only in some domains) as part of their promotional strategy. Using BILINGUAL PRODUCT NAMES, or offering MENUS OR COMMERCIALS in regional languages, contributes to the promotion of these language varieties and these activities could be used as an argument in favor of further language planning negotiations that aim to promote these language varieties. Therefore, the economic sector might become a valuable ally in language revitalization, regardless of the official attitude of the authorities.

Because some aspects of language are commonly held to be symbolic, that is emblematic of identity, dealing with language policy can arouse strong feelings and highlight the politics of language(s). The politics of language is firmly based on, and also reflects, the relationship between state, nation, ethnicity, language, and identity. It also relates to other issues, such as LANGUAGE RIGHTS and language protection, but also social exclusion or restriction based on the language(s) used, enforcement of monolingualism or promotion of multilingualism, migrants' languages, suppression of dialects, etc. Language rights are often treated as a part of human rights, and can be addressed by NONGOVERNMENTAL ORGANIZATIONS or INTERNATIONAL INSTITUTIONS (see later).

For many people, language policy refers to the goals and intentions of a group or institution, expressed in statements of a political nature. Language communities, activists, and revitalizers can of course express such POLITICAL STATEMENTS, too. While such statements vary with time and according to the political constellations of individual languages and their communities, they might include:

- public petitions, including those on social media,

- media campaigns, including those supported by famous people/celebrities, 
- nonviolent protest actions, rallies, and demonstrations,

- political lobbying through parties or individual MPs,

- lobbying through the MEPs (Members of European Parliament), some of whom have formed the Intergroup for Traditional Minorities, National Communities and Languages.

LANGUAGE PLANNING involves concrete actions or measures to implement policy decisions. Language planning as a concept is less political, although in practice, all aspects of language planning can become political when combined with power relations, and when requiring negotiations with institutions and policy makers. Both policy and planning need to take into account linguistic and extralinguistic factors. LINGUISTIC factors refer to features of the language itself (such as vocabulary or grammar), whereas EXTRALINGUISTIC factors refer to external influences such as politics, laws, economic factors, attitudes, ideologies, etc.

Traditionally language PLANNING is subdivided into three main types: corpus planning, status and prestige planning, as well as acquisition planning. These subcategories are distinct but interdependent, and each needs to be taken into account when planning language revitalization.

Corpus planning aims at adapting the language to meet the needs and objectives defined in policy making. Usually it seeks to increase the usage of a language by developing its linguistic resources, including vocabulary, grammar, and often writing conventions. For example, the Académie française was founded in 1653 to act as France's official authority on the usage, vocabulary, and grammar of the French language. Following the example of nation-state language planning activities, minority language communities often establish ACADEMIES, LANGUAGE BOARDS, or COMMITTEES of their own, with the objective of developing literary standards and eliminating 'impurities' from their language. The very existence of such language agencies is often a prerequisite for language-status recognition by authorities or amongst the general public. Authorities, for example, often require that minority language communities standardize their dialect clusters or linguistic continua to resemble 'developed' nationstate languages, whereas public opinion tends to consider nonstandardized language varieties as substandard, for example, dialects, slang, patois, etc. Even though it is not strictly necessary for the revitalization or maintenance of endangered languages, STANDARDIZATION might constitute a decisive argument in negotiations on official recognition of a language.

Status planning aims at changing the functions and uses of a language by influencing who uses it, in which situations and for which purposes. The status of a language can be raised or lowered in relation to other languages, and this often involves the change of its political or legal status. 
Negotiating the status of a language variety usually starts as a 'bottomup' initiative by a grassroots actor, and it is this aspect of language planning that most often involves intense power negotiations and deals with institutions and policy makers at various levels.

Grassroots movements and organizations use collective action at the community level to effect change at the local, regional, national, or international level. Grassroots movements are associated with 'bottom-up' decision-making and are considered more 'natural' or spontaneous than 'top-down' initiatives by more traditional power structures. Grassroots movements self-organize to inspire and encourage community members to engage and contribute to actions for their own community; therefore, the profile of their activities also matches language revitalization and language maintenance strategies. In the case of language revitalization programs, it is more and more frequent to have the active participation of engaged outsiders, be it nonnative new speakers of endangered languages or invited experts or researchers. Nevertheless, most studies of language revitalization programs stress that revitalization efforts must not be undertaken without the community of (potential) speakers, let alone against the community.

Grassroots movements not only represent (minority) communities in terms of language-related campaigns or negotiations, they can also advocate environmental issues of vital importance to local, Indigenous communities, such as the Ainu in Hokkaido/Japan, or communities in China and Brazil who oppose construction of dams on their life-giving rivers, or the Sorbs in Lusatia, whose land has been badly damaged by lignite mining. Good leadership is of great importance in 'bottom-up' language status planning actions vis-à-vis policy makers. Grenoble and Whaley ${ }^{1}$ stress that successful leaders have good organizational abilities and are sensitive to both individual differences and collective needs. According to Grenoble and Whaley, the following factors must be taken into account:

- an honest assessment of its own level of autonomy and the possibilities or limitations offered to it by its national structure,

- an honest assessment of human resources, and

- a clear articulation of what community members want to do with their language, along with an honest assessment of the attitudes, beliefs, and other obstacles that may prevent them from achieving their goals.

At times, it is the authorities themselves who resolve to settle the political status of a language variety through 'top-down' measures. However it would seem much more common for 'top-down' language policy to favor

${ }^{1}$ L.A. Grenoble and J. Whaley, Saving Languages: An Introduction to language revitalization. Cambridge: Cambridge University Press, 2006), p. 34. 
the state official language and subordinately rank nondominant languages as coofficial, auxiliary, or heritage, usually refusing any status to languages spoken by immigrants or to varieties that are labeled as dialects.

There are, though, counterexamples to this rule of thumb. A case in point might be the arrangements undertaken by the Portuguese state in reference to the Mirandese language. This geographically peripheral variety of the AsturLeonese language continuum, which is divided by the Spain-Portugal state border, had been used alongside official Portuguese. Its community had not striven for any particular status or undertaken language-planning activities until the 1990s. At the time, (Western) Europe was intensifying institutional efforts aimed at protecting and promoting the continent's language diversity. Portugal, despite being an active member of the European community, was nevertheless reluctant to support such institutional initiatives (e.g. refusing to sign or ratify the below-discussed European Charter for Regional or Minority Languages or to accede the European Bureau for Lesser-Used Languages). As a sort of replacement for the European initiatives for endangered languages, in 1999 the Republic of Portugal implemented an arbitrary set of legal measures in support of Mirandese, creating an entirely 'top-down' language maintenance program as far as corpus, status, prestige, and acquisition planning were concerned.

Prestige planning is in some ways different from status planning. It aims to make a language acceptable in contexts with high(er) prestige (like science, arts and literature, media) or to create opportunities for use in these types of settings, for example, by establishing new institutions (scientific, educational, artistic, etc.) which function in the language. Prestige planning is also about trying to influence language ideologies and language attitudes (see Chapter 8). Both 'top-down' and 'bottom-up' actions may aim to influence a language's prestige. Prestige planning also requires good public relations to ensure that policy and planning measures are accepted by the public; if this is not done, they are unlikely to succeed. It is also important to pay attention to the attitudes of majority populations, especially if public money is requested to support minority languages, as their taxes will be spent on it.

Dealing with policy makers to build up and strengthen the prestige of a community language might be quite challenging in the case of varieties that are perceived as ugly, un(der)developed, poor, corroded, spoiled, transitional, uneducated, etc. Throughout modern history many, if not most, nondominant languages all over the world have been stigmatized by nation-state societies with the above labels. Therefore, it is crucial for there to be a sustained DESTIGMATIZATION of nondominant language varieties, as well as the promotion of multilingualism and language diversity. For some communities this includes destigmatization at the lowest level of linguistic variation (e.g. dialectal). 
Destigmatization may sometimes lead to a CHANGE of STATUS of language varieties. For instance, a long-term 'bottom-up' campaign in favor of the endangered Ryukyuan languages has recently resulted in a 'topdown' agreement amongst many Japanese linguists to revise and restructure the hitherto linguistic classification of Ryukyuan as dialects of Japanese. Ryukyu is a southern archipelago of Japan, where each of the islands used to form a separate speech community. Recently the term 'Japanese language' has been replaced by 'Japonic languages' (or 'Japanese-Ryukyuan language family'), to include Ryukyuan as a complex of individual languages. This change of terminology clearly resulted in a reinforcement of revitalization efforts by some of the Ryukyuan insular communities.

In Europe, there has been a significant change in the prestige of individual language varieties, which were previously considered 'dialects', 'patois', 'platt', or 'speech'. This has been a result of the introduction of the term 'regional languages' by the European Charter for Regional or Minority Languages (see later). Following the introduction of the Charter, Germany decided to recognize Low German as Regionalsprache, Poland declared Kashubian a jezzyk regionalny, the Netherlands sanctioned Low Saxon and Limburgian as streektalen, whereas Scots and Ulster Scots gained recognition as regional languages in the United Kingdom. Other language communities, such as Venetian, Piedmontese or Sicilian in Italy, or Latgalian in Latvia, have actively sought the same status when strengthening their language revitalization efforts.

It is common for top-down policy and planning actions officially (but very superficially) to promote minority languages among minority communities themselves. This is often done instead of adopting a more inclusive and multifaceted campaigns, which simultaneously address minority speakers, government administration, societal authorities (experts, specialists, celebrities, distinguished activists), nongovernment organizations, and other policy actors. An example of the former may be the relatively ineffective Campaign promoting the use of national/ethnic minority/regional languages, carried out by the Polish government in 2014. This action was actually required by the European Charter for Regional or Minority Languages Committee of Experts' Report, so ministry officials hastily prepared and published some web materials and printed texts regarding certain minorities. These materials were then sent out to the very same minority institutions, who had actually been involved in preparing them. As might be expected, the next report that the Polish authorities sent to the Council of Europe referred to the 'effective promotion of use of minority languages'.

Achieving an internationally recognized language status should also be an important aim for a community when negotiating other language planning 
issues and policies with decision makers. One possible option is to apply for an ISO CODE, also known as Codes for the Representation of Names of Languages. These codes are used to classify languages by the Library of Congress in Washington, DC (USA) and by the lists of languages published by Ethnologue ${ }^{2}$ and Glottolog. ${ }^{3}$ Each language is assigned two or three letters - the most common three-letter codes are allotted by an institution called SIL International, ${ }^{4}$ which receives and reviews applications for requesting new language codes and for any changes to existing ones. Languages are eligible for a code if they are 'in use by a group of people for human communication, and [...] have been in use for a period of time'. For example, previously unrecognized language communities in Poland, including Kashubian, Silesian, and Wilamowice's Wymysiöeryś, have been successful in receiving the codes: $c s b, s z l$, and wym respectively. Kashubian is now a recognized regional language, while the two latter communities strive for state recognition as a part of their intense campaigns for language maintenance and revitalization. Although some applications for ISO codes are rejected, they are often given suggestions on how to modify proposals for resubmission.

Acquisition planning focuses on language transmission, language learning and teaching, (re)gaining language skills, language shift, bi- or multilingualism patterns, plus - in a wider context - foreign and second language learning. Occasionally acquisition planning is considered to be the same as language revitalization and maintenance. People assume that because schools are so good at killing languages, they can also save languages. Therefore, many minority communities perceive teaching their endangered language in school as THE objective and/or the main tool of language revitalization.

Acquisition policy is often not compatible with educational policy (of a state, region, group, denomination, etc.). However, every so often, an institutional language teaching curriculum is an important factor when negotiating language planning strategies such as revitalization, or when dealing with regulations. Granting the right to teach a language often means giving access to the education system, and providing teaching of a language (usually) means that it has official recognition. Therefore, communities often strive to have their language used in the school system as proof of the status of their language.

All over the world, educational authorities, as well as communities themselves, delude their societies and international institutions into believing that a couple of hours of lessons a week in a school curriculum is effective for

\footnotetext{
2 www.ethnologue.com/ 3 https://glottolog.org/glottolog/language

4 https://iso639-3.sil.org/
} 
language acquisition. This overlooks the difference between the teaching of a language (usually on a much less effective base than the official or and foreign languages) and teaching in a native language. Many minoritylanguage communities, not to mention the dominant society majorities or decision-making authorities, are not aware of issues relating to language acquisition in minority-majority situations, the bi-/multilingual development of a child, or effective teaching methods. Furthermore, when planning teaching provisions for minority languages, it seems quite common for both minority groups and educational authorities to ignore findings from psycholinguistics, multilingualism, and language acquisition studies. Therefore, more information and education are basic requirements when negotiating and developing a model of language teaching.

As in many revitalization efforts, community engagement is crucial when designing language acquisition strategies. One should remember that it is not the school itself that helps the young members of a community to acquire the language; when negotiating educational provisions with the policy makers, special attention should be devoted to the particular language teaching methods that will be used, such as (early) IMMERSION, LANGUAGE NESTS, BI-/MULTILINGUAL TEACHING, Or CONTENT AND LANGUAGE INTEGRATED LEARNING (CLIL, which can be understood as 'culture-and-language-integrated learning'). Not infrequent are cases when schools put children off the minority language, by teaching them in a mostly ineffective and boring way.

There are some minority-language teaching programs that were started entirely on the initiative of the communities, for example, the Diwan

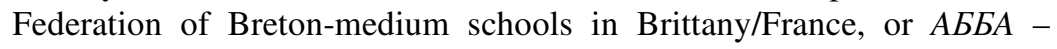
Association of Belarusian parents (now active as the Association for Belarusian-learning children and youth) in Podlachia/Poland. Through intense and far-sighted activity, both organizations managed to get recognition from educational authorities and introduce their community languages into mainstream school curricula.

The most effective teaching programs seem to be those that not only offer teaching of and in the community language, but also try to (re)create, (re)describe, research, and (re)interpret holistically the Indigenous worldview. Innovative curricula have been implemented at Sámi allaskuvla (Sámi University of Applied Sciences) in Guovdageaidnu=Kautokeino, Norway, Ka Haka 'Ula O Ke'elikōlani (University of Hawai'i College of Hawaiian) at Hilo, and in native Northern American institutions, who act in accordance with the Indigenous Nations' Higher Education Program as part of the World Indigenous Nations University initiative. Such institutions themselves become productive and influential policy makers, 
acting as language planners and community representatives at both regional and international levels.

Teaching of an (endangered) language must include many, if not all of the above aspects of language planning, and not solely a teaching network. A language should possess a developed corpus, and have an established status and a stable or growing level of prestige to function efficiently within the society.

Of course, some forms of language planning in revitalization contexts go beyond the simple three-part classification described above. One example is so-called LANGUAGE NORMALIZATION, which involves incorporating many aspects of language planning into holistic projects aimed at language empowerment in many social and public domains - for example, the normalización lingüística adapted for the communities of Basque, Catalan, Galician, Asturian in Spain.

Another example is the STANDARDIZATION of a language, which involves both corpus and status planning. A common opinion is that different human societies speak, or at least ought to speak, distinct languages with clear boundaries. This belief is strongly influenced by ideas of state nationalism originating in Europe. According to this belief, linguistic boundaries involve a clearly defined grammar, lexicon, phonetic inventory, and rules of usage, and, if possible, a writing system. Moreover it is commonly believed that linguistic boundaries should correspond to a particular political and geographical context. Generally many societies and authorities would gladly see the world neatly structured into distinct nation states, each with a fully fledged nationstate-language, a standardized stable communication system, with defined numbers of speakers, names of languages, norms, status, etc.

Historically the term STANDARD LANGUAGE was established over the course of the nineteenth century. It is only in the twenty-first century, however, that this otherwise technical term has become more prominent in modern discourse. The standard language ideology suggests that certain languages exist mainly, or only, in standardized forms. This belief affects the way in which speakers' communities think about their own language and about 'language' in general. One may say that speakers of these languages live in STANDARD LANGUAGE CULTURES. Given these widely held beliefs, it seems important to have regular information campaigns addressed to the authorities, policy makers, and also the dominant speech communities. These campaigns should shed light on the diversity of languages, demonstrating how linguistic variation occurs over time and territories, and according to social factors. This is especially important for minority, lesser-standardized, and endangered languages. Majorities should be systematically familiarized with terms and ideas such as language revival, maintenance, spread, modernization, normalization, etc. 
Since the mid-twentieth century, language planning processes have gained a supra-national or trans-national dimension, particularly in light of a global interest in (linguistic) human rights. Minority language communities and, sometimes, individual speakers, may refer to certain international legal instruments when dealing with state-level authorities.

Worth mentioning are the following:

- United Nations Universal Declaration of Human Rights

- United Nations International Covenant on Civil and Political Rights

- United Nations Declaration on the Rights of Indigenous Peoples

- United Nations Declaration on the Rights of Persons belonging to National, Ethnic, Religious and Linguistic Minorities. ${ }^{5}$

These can be referred to or invoked when (re)claiming rights to native heritage and Indigenous languages. It should be mentioned, however, that the international language rights regimes has, in recent times, come under harsh criticism for their vagueness, ineffectiveness and lack of consistent legal instruments of enforcement.

Nevertheless, one useful outcome of the UNESCO programs concerning endangered languages and linguistic diversity is its 2003 framework for assessing the relationship between attitudes as articulated by government policy and language vitality. It differentiates six levels of explicit policy and/or implicit attitudes toward the dominant and subordinate languages (vis-à-vis the national language) by governments and institutions:

Equal support: All of a country's languages are valued as assets. All languages are protected by law, and the government encourages the maintenance of all languages by implementing explicit policies.

Differentiated support: Nondominant languages are explicitly protected by the government, but there are clear differences in the contexts in which the dominant/official language(s) and nondominant (protected) language(s) are used. The government encourages ethnolinguistic groups to maintain and use their languages, most often in private domains (as the home language), rather than in public domains (e.g. in schools). Some of the domains of nondominant language use enjoy high prestige (e.g. at ceremonial occasions).

Passive assimilation: The dominant group is indifferent as to whether or not minority languages are spoken, as long as the dominant group's language is the language of interaction. Though this is not an explicit language policy, the dominant group's language is the de facto official language. Most domains of nondominant language use do not enjoy high prestige.

5 The 1996 Universal Declaration of Linguistic Rights has not gained formal approval from UNESCO. 
Active assimilation: The government encourages minority groups to abandon their own languages by providing education for the minority group members in the dominant language. Speaking and/or writing in nondominant languages is not encouraged.

Forced assimilation: The government has an explicit language policy declaring the dominant group's language to be the only official national language, whereas the languages of subordinate groups are neither recognized nor supported.

Prohibition: Minority languages are prohibited from use in any domain. Languages may be tolerated in private domains.

Minority language communities in European states might also use and invoke some of the legal provisions concerning the rights of Europe's minorities and their languages. In the 1990s and 2000s, institutionalized and legally binding protection and promotion of ethnic and linguistic diversity in Europe dominated the agenda of institutions like the Council of Europe, who prepared and promoted three significant documents:

- European Convention on Human Rights,

- Framework Convention for the Protection of National Minorities, and particularly

- the European Charter for Regional or Minority Languages.

The latter has been proclaimed the first international instrument directed solely at the question of language, setting language rights firmly in the context of the value of cultural diversity for its own sake. The preamble to the Charter states, for example, that 'the protection of the historical regional or minority languages of Europe, some of which are in danger of eventual extinction, contributes to the maintenance and development of Europe's cultural wealth and traditions'. Another innovation has been the implementation instruments of the Charter, as the selection of provisions adopted for each individual language depended on their situation. Member states of the Council of Europe have been vigorously encouraged to sign and ratify the Charter, and countries that have implemented it have been submitted to periodical monitoring by the Committee of Experts, who were to be independent specialists.

After almost thirty years, views on the Charter's efficacy are divided. It is in force in twenty-five states, but the attitudes of individual states vary considerably - from diligent fulfillment of all the commitments (in states that already had developed systems of support for endangered language communities) to propaganda simulation (as in the above-mentioned case of Poland). This is not to mention the states that refuse to apply the Charter in the foreseeable future (as in the interesting case of Portugal, referred to earlier). Indeed, some state authorities, in accordance with their general 
language policies, refuse to officially recognize (or to support in any form) languages and language communities (such as Wymysiöeryś or Silesian in Poland, Rusyn in Ukraine). Hardly any appeals made by language communities in Europe regarding the legal obligations set out in the Charter have proven successful.

\section{FURTHER READING}

Grenoble, L. A. and Whaley, J. (2006). Saving Languages: An Introduction to language revitalization. Cambridge University Press.

Olko, J., Wicherkiewicz, T., and Borges R., eds. (2016). Integral Strategies for Language Revitalization. Warsaw: Faculty of 'Artes Liberales', University of Warsaw. http://revitalization.al.uw.edu.pl/Content/Uploaded/Documents/integralstrategies-a91f7f0d-ae2f-4977-8615-90e4b7678fcc.pdf.

Sallabank, J. (2013). Attitudes to Endangered Languages Identities and Policies. Cambridge University Press.

Tollefson, J. W. and Pérez-Milans M., eds. (2018). The Oxford Handbook of Language Policy and Planning. Oxford University Press.

UNESCO Ad Hoc Expert Group on Endangered Languages (2003) Language vitality and endangerment. Document submitted to the International Expert Meeting on UNESCO Programme Safeguarding of Endangered Languages, Paris, 10-12.03.2003. www.unesco.org/new/fileadmin/MULTIMEDIA/HQ/CLT/pdf/ Language_vitality_and_endangerment_EN.pdf

\subsection{Language Revitalization and Academic Institutions: Refocusing Linguistic Field Methods Courses}

\section{Eric W. Campbell, Griselda Reyes Basurto, and Carmen Hernández Martínez}

Language revitalization can only be successful if it is community-driven, addressing the needs and goals of community members. There is therefore an inherent challenge for carrying out revitalization projects within academic institutions, where Indigenous community members are typically under-represented, and where the primary focus is on research - that is, research in the narrower sense of systematic investigation for the purpose of advancing (Western) scientific knowledge. Here we discuss one model for initiating or advancing language revitalization or maintenance projects in a graduate-level field methods course in a US academic institution.

Not all graduate linguistics programs value language revitalization, language documentation, or even linguistic fieldwork, and not all programs offer courses on these topics. When field methods courses are offered, they often involve a single community member, and the primary goal is to do linguistic analysis through elicitation. Such courses follow a traditional, colonial model that reinforces the 
divide between researchers and a research 'subject'. In field methods courses that follow such a model, community-driven language revitalization may be impossible.

The traditional mold can be broken by using a field methods course to establish a community-based language research project, or by building the course into an existing one. For example, as part of an ongoing collaboration, University of California, Santa Barbara (UCSB) linguists and the Mixteco/Indígena Community Organizing Project (MICOP) recruited community members for UCSB's 2015-16 and 2017-18 field methods courses. MICOP's mission is to aid, organize, and empower the migrant community along California's central coast (see Capsule 6.2), and the courses have advanced MICOP's mission by supporting a community-based language research and activism project (see Capsule 13.2).

In these field methods courses at UCSB, graduate students and community members work in close collaboration to gain extensive training in language documentation and linguistic analysis in a community-based research model. While traditional field methods activities such as analysis of the sound system (phonology), orthography design, documentation of lexis (vocabulary), audiovideo recording, transcription and translation, grammar writing, ethics, and archival deposit preparation are part of the course, graduate students and community members learn these skills together. The activities and outcomes are shaped by the goals and interests of the community members, and a special focus is placed on developing practical materials for language maintenance and use in the community, such as trilingual illustrated text collections, games, and language activities that are shared with the wider Indígena community of Ventura County, California during MICOP's monthly meetings.

Crucially the course provides extensive training to community members who then go on to use its tools and methods as leaders in their own language maintenance or pedagogical activities in the community. While some graduate students in the course pursue or continue research in other subfields of linguistics or with communities in other parts of the world, other students continue working with and supporting the local community members in their language-related activities as they themselves progress through their graduate education. Although not every institution is located near a potential partner community, field methods courses can refocus institutional resources to train students in a community-based model in which course activities and assignments are determined by the interests and goals of the speaker in order to support their language community. 